\title{
Article
}

\section{Regulating hatred of devils and demons?}

\author{
Alkiviadou, Natalie \\ Available at http://clok.uclan.ac.uk/24285/ \\ Alkiviadou, Natalie ORCID: 0000-0002-4159-8710 (2018) Regulating hatred of \\ devils and demons? International Journal of Discrimination and the Law, 18 \\ (4). pp. 218-236. ISSN 1358-2291
}

It is advisable to refer to the publisher's version if you intend to cite from the work. http://dx.doi.org/10.1177/1358229118796029

For more information about UCLan's research in this area go to http://www.uclan.ac.uk/researchgroups/ and search for < name of research Group>.

For information about Research generally at UCLan please go to http://www.uclan.ac.uk/research/

All outputs in CLoK are protected by Intellectual Property Rights law, including Copyright law. Copyright, IPR and Moral Rights for the works on this site are retained by the individual authors and/or other copyright owners. Terms and conditions for use of this material are defined in the policies page.

\section{CLoK}

Central Lancashire online Knowledge www.clok.uclan.ac.uk

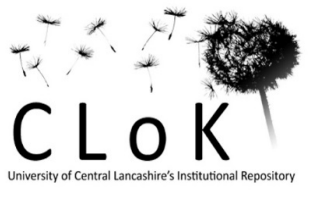


Regulating hatred

Of devils and demons?

Natalie Akiviadou,

\section{Abstract}

Hate speech and hate crime are an anathema to any society. On a United Nations level, the central tools to tackle such hatred are Article 20(2) of the International Covenant on Civil and Political Rights and Article 4 of the International Convention on the Elimination of All Forms of Racial Discrimination. On a Council of Europe level, the Additional Protocol to the Cybercrime Convention tackles racist and xenophobic material, threats and insults as well as revisionist rhetoric transmitted and disseminated through computer systems. On a European Union level, there is the Framework Decision on Racism and Xenophobia. In none of the above-mentioned instruments do we find provisions on homophobic and transphobic speech and crime, nor are there equivalents of documents such as the Framework Decision with the thematic of homophobia and transphobia. This creates a hierarchy of hate, with some forms of hate considered more important than others by the aforementioned institutions, a reality that goes against the very essence of international human rights law.

Keywords Hate speech, homophobia, transphobia, discrimination, human rights, hate crime

\section{Introduction}

Hatred as manifested by hate speech and hate crime is a menace to any society and the values of equality, respect and solidarity, as enshrined in all international and European human rights documents. Hate speech and hate crime are interrelated and interconnected, targeting one or more inherent characteristics of their victims. As such, these phenomena seek to transmit messages of hatred and intolerance towards such characteristics, thereby causing harm on three scales, namely, the micro-scale (the victim), the mesoscale (the victim group) and the macro-scale (society, through, e.g. the deterioration of community cohesion). - There exist several international and European instruments which seek, directly or indirectly, to deal with hate speech and hate crime. The devastating effects of World War II prompted the international community to establish infrastructure that could prevent the reoccurrence of such aggression, hence the birth of international human rights law as we know it today. The first symbolic movement of the United Nations (UNs) ${ }^{2}$ was the, albeit 
non-binding, Universal Declaration of Human Rights which was 'born out of the experience of the war that had just ended'. Within a European framework, the Council of Europe was established to promote peace and unity among its Member States and prevent the reoccurrence of the atrocities witnessed in the 1940s. ${ }^{4}$ The two directly relevant documents of the UN, in the sphere of regulating hate speech, are the International Covenant on Civil and Political Rights (ICCPR) and the International Convention on the Elimination of All Forms of Racial Discrimination (ICERD) discussed in the following. More recent documents have emanated, on a European level, and are directly related to hate speech and/or hate crime rather than falling within the general framework of umbrella phenomena such as racism and xenophobia. These are the Council Framework Decision on combating certain forms and expressions of racism and xenophobia by means of criminal law and the Additional Protocol to the Cybercrime Convention, concerning the criminalization of acts of a racist and xenophobic nature committed through computer systems. The striking issue that will be developed and demonstrated in this article is that the international and European framework has, from the time of its inception until 2008, the year in which the very last relevant document was agreed upon, focused solely on certain types of hate speech and hate crime which target racial and religious groups, with no convention or other document, to date, prohibiting or regulating homophobic or transphobic speech and crime in any form or way. In the European framework, which serves as the contextual premise of this article, such speech occurs in contexts such as political debates, debates concerning Lesbian, Gay, Bisexual, Transgender (LGBT) rights and events and in statements made by religious figures, with persons often being depicted as 'unnatural, diseased, deviant, linked to crime, immoral or socially destabilising'. $\underline{5}$ At the same time, hate crime against LGBT persons is 'a prevalent phenomenon that has an impact on gay men, lesbians, bisexual men and women and transgender persons in various ways' $\underline{6}$ The above-mentioned reality has resulted in what can be referred to as a 'hierarchy of hate', ${ }^{7}$ with some forms of hate speech and hate crime simply considered as being more important to deal with than others. This article is not conducting a theoretical analysis on if and/or how hate speech is to be curtailed (or not $)^{\underline{8}}$ nor is it seeking to examine hate crime models ${ }^{9}$ as these issues have already been looked at extensively in scholarly contributions. Instead, this article is illustrating the aforementioned hierarchy and demonstrating the inherent malaise in this hierarchy. To this end, the article will look at the (potential) meanings of hate speech and hate crime, assess the relevant international and European legal provisions that can be used to tackle these phenomena, consider any positive developments to close the gap of prioritization and 
examine good practice examples, on national levels, which have superseded the obligations imposed by the international and European level.

\section{Definitional and conceptual framework}

Hate speech

The possible routes and effects of hate speech have been discussed by several academics. Belavusau argues that hate speech is 'deeply rooted in the ideologies of racism, sexism, religious intolerance, xenophobia, and homophobia'. ${ }^{10}$ As for relevance and utility, Smolla argues that hate speech 'states no fact, offers no opinion, proposes no transaction, attempts no persuasion'. 11 On the premise of this argumentation, Sagle held that, as a result, hate speech 'cannot contribute to a societal dialogue and therefore can be ethically curtailed'. $\stackrel{12}{ }$ Greenawalt takes it a step further, holding that such speech has damaging effects given that 'epithets and slurs that reflect stereotypes about race, ethnic group, religion and gender may reinforce prejudices and feelings of inferiority in seriously harmful ways'. 13 The severe impact of hate speech can be discerned from the statement of the UN Committee against Torture which underlines the interrelation between hate speech and torture, holding that 'hate speech is symptomatic of an environment of hostility in which torture and other acts of cruel, inhuman or degrading treatment or punishment are more likely to manifest'. .4 Although the term hate speech appears in academic articles, policy documents and in other spheres, such as the media and daily life, there is no real agreement among States as to what hate speech actually is. $\frac{15}{}$ Instead, States and institutions adopt their own understanding and conceptualization of hate speech, $\underline{16}$ resulting in varying thresholds of hate between such definitions. The central tension in agreeing on a universal definition is determining where the line between free speech and hate speech is to be drawn. The Committee on the Elimination of All Forms of Racial Discrimination (CERD) discussed the line between free speech and hate speech in its 2001 Concluding Observations on the United States. In discussing Article 4 of the ICERD, which prohibits, inter alia, the dissemination of racist ideas, the Committee argued that this prohibition is not in contravention of free speech as this freedom 'carries special duties and responsibilities, among which is the obligation not to disseminate racist ideas' ${ }^{17}$ Further, in General Recommendation 15, the CERD underlined that 'the prohibition of the dissemination of all ideas based upon racial superiority or hatred is compatible with the right to freedom of opinion and expression'. 18 Therefore, the UN's scale clearly tilts in the direction of freedom from racial discrimination when confronted with racist speech. However, given that there are no equivalent UN conventions or provisions within other conventions tackling speech directed 
at, for example, persons due to their sexual orientation, the above balancing test cannot be automatically deemed to apply to other types of hate speech.

In 2008, the European Union (EU) sought, among other things, to rectify the abovedescribed definitional gap through the Framework Decision, which set out a line to be followed by Member States in relation to some forms of hate speech. Interestingly, though, and as will be discussed in 'Council framework decision 2009/913/jha of 28 November 2008 on combating certain forms and expressions of racism and xenophobia by means of criminal law' section, this document does not define hate speech nor does it make any reference to this term in its text or title. Instead, Article 1, therein, prohibits the public incitement to violence or hatred directed against a group of persons or a member of such a group defined by reference to race, colour, religion, descent or national or ethnic origin. It must be noted that, notwithstanding the Framework Decision, and, as recently underlined by the European Parliament, the conceptualization of hate speech differs from State to State, with the parliament illustrating this point by referring to the relatively broad definition adopted in Germany and a narrower one in the Czech Republic. ${ }^{19}$ Even though the Framework Decision sought to bring about cohesion among Member States, both in the framework of conceptualization of hate speech and also in terms of approach to hate speech and hate crime, the latest transposition report noted that 'at present it appears that a number of Member States have not transposed fully and/or correctly all the provisions of the Framework Decision'. $\underline{20}$

The approach adopted by the Framework Decision has also been taken by the European Commission in the Code of Conduct on Countering Illegal Hate Speech Online, which was agreed with four IT companies, Facebook, YouTube, Twitter and Microsoft, thereby extending the Framework's impact within the regulatory framework of the Commission and the four companies. The approach of the Framework Decision is narrower than that of Article 20(2) of the ICCPR, which does not offer a definition of hate speech, per se, but, instead, prohibits any advocacy of national, racial or religious hatred that constitutes incitement to discrimination, hostility or violence. It is the only UN document which comes as close as possible to a definition. The non-binding Recommendation of the Council of Europe Committee of Ministers on hate speech is one of the only documents of this level to provide an actual definition of hate speech. It holds that this term is to be

understood as covering all forms of expression which spread, incite, promote or justify racial hatred, xenophobia, anti-Semitism or other forms of hatred based on intolerance, 
including intolerant expression by aggressive nationalism and ethnocentrism, discrimination and hostility against minorities, migrants and people of immigrant origin. $\underline{21}$

The threshold must be read in line with the European Court of Human Rights (ECtHR)'s position, which extends free speech to ideas that 'shock, offend or disturb'. $\underline{2}$ The definition is extensive insofar as it contains the justification of hatred but limited in that it only encapsulates certain characteristics related to ethnicity and migrant origins. Although no reference is made to minorities, there is no indication that this term contains sexual minorities and, given the general spirit of the definition, it is more probable than not that it does not seek to incorporate sexual minorities. The ECtHR has also sought to elucidate the meaning of hate speech. For example, in Gündüzv. Turkey, it held that this entails 'all forms of expression which spread, incite, promote or justify hatred based on intolerance including religious intolerance'. $\underline{23}$ Once again, as with the Committee of Ministers' definition, the Court adopted a low threshold, given that justification of expression was also considered to fall within the framework of hate speech. Interestingly, in Vejdeland v. Sweden, which was the first case brought to the ECtHR that dealt with homophobic speech and particularly the dissemination of homophobic leaflets in school lockers, the Court held that it is not necessary for the speech 'to directly recommend individuals to commit hateful acts' $\underline{24}$ since attacks on persons can be committed by 'insulting, holding up to ridicule or slandering specific groups of the population'. $\underline{25}$

This is of particular importance to the conceptualization of hate speech by the Court in that it does not put forth a requirement of a direct nexus between hate speech and an actual call for a hateful act. Instead it looks at hate speech in a way that recognizes that the speech itself is harmful and forbidden if it insults, ridicules or slanders certain groups. A report of the Fundamental Rights Agency of the EU holds that hate speech 'refers to the incitement and encouragement of hatred, discrimination or hostility towards an individual that is motivated by prejudice against that person because of a particular characteristic'. $\underline{26}$ This definition may not contain the lower threshold of justification as the Committee of Minister's Recommendation does. However, it is broader in nature in that it incorporates the generic ground of a 'particular characteristic' as protected, thereby embracing characteristics ranging from ethnicity to gender identity. $\frac{27}{}$ Therefore, just by looking at definitions on an EU and Council of Europe level, one can discern variations both in terms of thresholds that need to be met in relation to hate and in respect of the grounds which are considered to be protected characteristics. 
From the above-mentioned approaches to hate speech and the variations, therein, although some common elements can be discerned, it could be argued that 'hate speech seems to be whatever people choose it to mean'. $\underline{28}$ The European Parliament has recognized the weaknesses of the lacking definitional consensus on hate speech and called on the Commission to look into the feasibility of establishing a common legal definition of hate speech in the EU. It did so within the framework of the current efforts of the Commission and the four IT companies to tackle online hate speech through the Code of Conduct. The parliament underlined that these efforts should be reinforced by 'a combined effort by Member States to agree on a legal definition of hate speech'. $\underline{29}$ Further, it must be noted that, notwithstanding the position of the ECtHR in Vejdeland v. Sweden, namely that homophobic speech is just as damaging as racist speech, $\underline{\underline{30}}$ there is yet to be a tool that directly incorporates the issue of homophobic or transphobic speech in a concrete definitional framework of hate speech, with the EU's Framework Decision choosing to focus solely on other grounds related to ethnicity and religion.

\section{Hate crime}

As with hate speech, there is no internationally accepted definition of a hate crime, nor is one provided for on a European level. The Organization for Security and Cooperation in Europe (OSCE) holds that hate crimes are:

...criminal acts committed with a bias motive. It is this motive that makes hate crimes different from other crimes. A hate crime is not one particular offence. It could be an act of intimidation, threats, property damage, assault, murder or any other criminal offence. The term 'hate crime' or 'bias crime', therefore, describes a type of crime, rather than a specific offence within a penal code. A person may commit a hate crime in a country where there is no specific criminal sanction on account of bias or prejudice ${ }^{2}$

As such, hate crimes are characterized by two interrelated elements, firstly that there exists a criminal act and, secondly, that the act is committed out of bias motivation, namely, that the 'perpetrator chose the target of the crime based on the victim's protected characteristic'. $\frac{31}{}$ As such, hate crimes are different to other types of crimes due to the perpetrator's motivation but also the multilevel impact of the crime. As mentioned in the introduction, as with hate speech, hate crime has individual, group and societal impacts. McLaughlin and Muncie underline that victims are targeted due to their identity and this, in turn, terrorizes not only the victim but also the group which shares the targeted characteristics. $\frac{32}{}$ It is within this frame of reasoning that the OSCE recognizes that a hate 
crime is also a message crime and a symbolic crime. $\frac{33}{}$ Empirical research has demonstrated that 'there is a qualitative difference to the impact of hate crimes as compared to non-hate motivated incidents'. $\underline{34}$ Data from the Crime Survey for England and Wales revealed that hate crime victims were more affected by the incident than victims of other crimes $(92 \%$ in comparison with $81 \%$ ) with $39 \%$ of hate crime victims being 'very much' affected in comparison with $13 \%$ of victims of other crimes; $39 \%$ of victims felt vulnerable and underconfident after the hate crime in comparison with $17 \%$ of non-hate crime victims. $\frac{35}{\text { In }} 2015$, Iganski and Sweiry underlined that information on the 'spatial and behavioural consequences of hate violence $\underline{36}$ is limited but that analysis from limited data in England and Wales demonstrated, for example, that:

in the case of victims of household crime, it is evident that hate crime victims are more likely to report moving home and being more alert and less trusting of other people, while victims of otherwise motivated household crime are more likely to report increasing the security of their vehicles and valuables..$\underline{37}$

The above-mentioned authors also linked the recent disproportionate number of hate crimes committed against Jews in France to the migration of this group from the country. $\underline{38}$

In Nachova and Others v. Bulgaria, which involved the killing of two Bulgarian nationals of Roma origin by the Police, the ECtHR recognized the nature of hate crimes (in particular racist crimes) and the importance of recognizing the motivation of such crimes, holding that:

it is particularly important that the official investigation is pursued with vigour and impartiality, having regard to the need to reassert continuously society's condemnation of racism and ethnic hatred and to maintain the confidence of minorities in the ability of the authorities to protect them from the threat of racist violence.

This approach was further enforced by the Court in Šečić v. Croatia, which involved the beating of a Roma person by a skinhead group, recognizing that the duty to determine the racist motive extends to crimes committed by private individuals. $\frac{39}{}$ In Identoba and Others v. Georgia, the ECtHR extended principles it had previously applied to racist violence to the framework of homophobic violence and underlined the sheer importance of investigating hateful motives by holding that: 
treating violence and brutality with a discriminatory intent on an equal footing with cases that have no such overtones would be turning a blind eye to the specific nature of acts that are particularly destructive of fundamental rights. $\underline{.4}$

Although the elements of hate crime have been underlined by the OSCE and the ECtHR has highlighted the need to unravel hateful motives behind such crimes, and, while documents such as the ICERD prohibits acts of violence against groups of persons characterized by, among others, their colour or ethnic origin, there is no direct definition of hate crimes within international or European documents. The closest a document gets to extrapolating on how hate crime is to be dealt with is the EU Framework Decision on Racism and Xenophobia, which holds that racist and xenophobic motivation is to be considered an aggravating circumstance or to be taken into consideration in the determination of penalties by courts. It must be underlined that the Framework decision does not actually define hate crime. Once again, in the conceptualization of how hate crime is to be approached, elements such as sexual orientation and gender identity are missing from the provisions.

\section{The principle of non-discrimination}

The above-mentioned section sought to elucidate the meanings of hate speech and hate crime and demonstrate the difficulties which lie in defining hate speech particularly due to free speech issues. Further, by looking at available definitions and conceptualizations of the two phenomena, it also sought to demonstrate the enhanced focus of international and European institutions on hate speech and hate crime directed at characteristics related to ethnicity and religion rather than to sexual orientation and gender identity. This section sets out the meaning of non-discrimination, which lies at the heart of any efforts that seek to tackle hate speech and hate crime, given that these phenomena are an anathema to the overarching requirement of a democratic society, namely the prohibition of discrimination on the basis of identity and inherent characteristics.

General Comment 18 of the Human Rights Committee (HRC) underlines that 'non discrimination, together with equality before the law and equal protection of the law without any discrimination, constitute a basic and general principle relating to the protection of human rights'. 41 The Charter of the UNs sets out the purposes of the UN which are to, inter alia, 'achieve international cooperation... in promoting and encouraging respect for human rights and for fundamental freedoms for all without distinction as to race, sex, language, or religion'. ${ }^{42}$ Article 13(1) of the Charter recognizes that the UN General Assembly will assist 'in the realization of human rights and fundamental freedoms for all without distinction as 
to race, sex, language or religion'. Article 2 of the Universal Declaration of Human Rights (UDHR) provides that 'everyone is entitled to all the rights and freedoms set forth in this Declaration, without distinction of any kind, such as race, colour, sex, language, religion, political or other opinion, national or social origin, property, birth or other status'. Article 7 of the same Declaration incorporates the theme of incitement to discrimination, providing that 'all are entitled to equal protection against any discrimination in violation of this Declaration and against any incitement to such discrimination'. The general nondiscrimination clauses of the ICCPR and the International Covenant on Economic, Social and Cultural Rights, in the form of Article 2(2) in both documents adopt the same wording and approach as Article 2 of the UDHR. The sheer importance of Article 2(2) is reflected in Article 4(1) of the ICCPR, which deals with derogations in times of emergency and holds that derogation from State obligations under certain articles is allowed insofar as these do 'not involve discrimination solely on the ground of race, colour, sex, language, religion or social origin'. The principle of non-discrimination is also incorporated into the European Convention on Human Rights. Article 14, which is very similar to its UN counterparts, mentioned above, holds that

the enjoyment of the rights and freedoms set forth in this Convention shall be secured without discrimination on any ground such as sex, race, colour, language, religion, political or other opinion, national or social origin, association with a national minority, property, birth or other status.

In the framework of the current discussion, there is no reference to sexual orientation or gender identity in the above-mentioned articles. However, on a UN level, in the case of Toonen v. Australia, the HRC held that Article 2(1) protects persons from discrimination on the grounds of their sexual orientation. ${ }^{43}$ Since that decision, the HRC has urged States to guarantee equal rights regardless of sexual orientation and has embraced legislation which incorporates sexual orientation as a protected characteristic in the realm of nondiscrimination. ${ }^{44}$ In relation to the ECHR, there is a reference to 'other status' which could logically incorporate these grounds, albeit lacking an explicit reference to them as is made with other grounds such as language and religion. However, the ECtHR has elucidated the meaning by recognizing that the prohibition of discrimination, as provided for in Article 14, includes discrimination due to sexual orientation ${ }^{45}$ and transexuality, and therefore gender identity, thus covering both themes under consideration. $\underline{46}$ 
The principle of non-discrimination lies at the heart of the functioning of the EU. It is directly referred to in EU Treaties, such as Articles 2 and 3 of the Treaty on the EU and Article 10 of the Treaty on the Functioning of the European Union (TFEU). Article 2 holds that the EU is founded on values including, among others, non-discrimination while Article 3, therein, imposes a positive duty on the Union to combat discrimination. Importantly, Article 10 of the TFEU provides that in defining and implementing its policies and activities, the Union shall aim to combat discrimination based on sex, racial or ethnic origin, religion or belief, disability, age or sexual orientation'. It must be noted that the Charter was the first human rights document directly to prohibit discrimination on the grounds of sexual orientation.

Therefore, the generic clauses of UNs and Council of Europe documents refer to grounds such as race and religion but not to sexual orientation or gender identity. However, the HRC has recognized that sexual orientation (not gender identity) can be a protected characteristic in this framework while the ECtHR has recognized that, as well as the grounds explicitly set out in Article 14, such as race and religion, sexual orientation and gender identity are protected characteristics. It was the EU's Charter that explicitly recognized the ground of sexual orientation in the realm of non-discrimination, adding it for the first time to the regular list of grounds such as race and religion. However, the Charter applies only insofar as the Member States are applying EU Law. Notwithstanding the normative but also practical importance of this development, the exclusion of gender identity from these grounds is to be perceived as a weakness when taking into account the general development of human rights law and the increased recognition by international institutions and civil society that persons are discriminated against as a result of their gender identity..$^{47}$

\section{International regulatory framework: The UNs}

The ICERD: Article

Article 4 of the ICERD prohibits racist ideas, acts, groups and the financing of such groups. Important for the present discussion is part (a) of the article which holds that State Parties:

Shall declare an offence punishable by law all dissemination of ideas based on racial superiority or hatred, incitement to racial discrimination, as well as all acts of violence or incitement to such acts against any race or group of persons of another colour or ethnic origin, and also the provision of any assistance to racist activities, including the financing thereof. 
The importance of this article in relation to the fight against racist speech, and racial discrimination more generally, is indisputable. It has been described as 'the most important article in the Convention', ${ }^{48}$ In its first General Recommendation, the CERD noted that the implementation of Article 4 is 'obligatory under the Convention for all States parties'. ${ }^{49}$ Further, Article 4 has been deemed to be 'the principal vehicle for combatting hate speech'.$\underline{50}$ Notwithstanding the significance and relevance of this comment in relation to racist speech, it is not applicable to hate speech, more generally, which entails characteristics beyond those incorporated into Article 4 and the Convention. The striking element of this article is that it embraces a particularly low threshold in comparison with other international and European provisions, as will be demonstrated with the analysis of other instruments discussed in the following. This can be seen from the prohibition of the dissemination of racist ideas without such ideas having to constitute, for example, advocacy for discrimination, hostility or violence as is the case with Article 20(2) ICCPR. This demonstrates the particular severity the UN attached, at least at the time, to racist ideas although there is no explanation as to the vast variation in threshold between the ICCPR and the ICERD given that they were both drafted in a similar time frame.

In relation to racist crime, the ICERD does not explicitly refer to racist crime but, instead, calls for the punishment of racist acts of violence. The reference in Article 4 to the punishment of racist acts of violence is rather bizarre given that acts of violence, racist or not, are anyhow punishable by law and so the substance of this reference is unclear. In light of this, one would have expected the provision to refer to some sort of increased penalty for such acts or the consideration of racist motive as an aggravating circumstance. All in all, not much has been done on a UN level to elucidate the meaning and treatment of hate crime.

In light of the above, three conclusions can be drawn in relation to the ICERD. Firstly, it has a very broad conceptualization of what should be prohibited speech, which includes the mere dissemination of racist ideas. Secondly, no other characteristics, which fall prey to haters, have a Convention of their own, as racial origin, ethnic origin or colour have in the form of the ICERD and, particularly Article 4 therein, placing it at the peak of protection.

ICCPR: Article 20(2)

Article 20(2) of the ICCPR provides that:

Any advocacy of national, racial or religious hatred that constitutes incitement to discrimination, hostility or violence shall be prohibited by law. 
This article does not provide for a human right, like the other articles of the Covenant, but, instead, indirectly sets out a limitation to the exercise of rights which could lead to the prohibited behaviour. The rights which are directly limited by this article are expression, assembly and association as it is through those mechanisms that advocacy of such hatred could be pursued. This reality could cause some possible tensions between the prohibition of the aforementioned advocacy and the exercise of rights. In this realm, the HRC discussed the relationship between Article 19 (freedom of expression) and Article 20 holding that 'Articles 19 and 20 are compatible with and complement each other. The acts that are addressed in Article 20 are all subject to restriction pursuant to Article 19, paragraph 3'. This position regarding duties and responsibilities related to the exercise of free speech can also be extended to the other two rights, mentioned above, which can also be vehicles for the prohibited advocacy. The threshold of this article is higher than Article 4 ICERD, discussed immediately above, in that Article 4 prohibits the dissemination of racist ideas whereas Article 20(2) requires that there has to be advocacy of hatred rather than only a dissemination of hateful ideas.

This is a significant article in the regulation of hate speech, with no counterpart in the ECHR. However, notwithstanding its importance, this article limits itself to national, racial or religious hatred and makes no reference to other characteristics, which may be targeted such as sexual orientation and gender identity. However, Article 19, an NGO working on freedom of expression recommends that Article 20(2) is to be read in light of the list of characteristics set out in Article 2 of the Covenant, thereby incorporating sexual orientation and gender identity into Article 20 (2). $\frac{51}{}$ However, although this would partially circumvent limitations to Article 20(2) in terms of the hierarchy of particular types of hate, Article 2 does not, in fact, refer to sexual orientation or gender identity but, instead, to 'other status' that could be interpreted to include this and, as noted by the HRC in Toonen, should be interpreted like this in the realm of sexual orientation. Nevertheless, the hierarchy issue is still a thorn since, for example, advocacy of hatred based on sexual orientation is not automatically prohibited as is its racial hatred counterpart while gender identity has not been formally considered by the HRC to fall within the realm of Article 2's 'other status'. In sum, three conclusions can be drawn. Firstly, Article 20(2) has a higher threshold than Article 4 ICERD in that it prohibits advocacy rather than mere dissemination of ideas. Secondly, it is particularly significant in the framework of hate speech regulation, as it has no counterpart in its European equivalent, namely the European Convention on Human Rights. Thirdly, notwithstanding its importance, it is lacking insofar as grounds for hatred are concerned, 
limiting itself only to particular types of hatred, ousting sexual orientation and gender identity from protection against hatred.

\section{The regulation of hate in European law}

Council framework decision 2009/913/jha of 28 November 2008 on combating certain forms and expressions of racism and xenophobia by means of criminal law

The Framework Decision on Racism and Xenophobia is the first document of this legal weight to have been developed and adopted on an EU level tackling the theme of hate speech, albeit only in the spheres of racism and xenophobia. While the Framework Decisions seeks to punish both hate speech and hate crime, these terms are not found in the title or text of the document. Moreover, there is no equivalent Framework Decision or other EU document dedicated to tackling hate speech more generally (incorporating grounds such as sexual orientation and gender identity).

Article 1 provides that Member States must punish incidences of publicly inciting to violence or hatred against a particular group defined by reference to race, colour, religion, descent or national or ethnic origin through public dissemination or distribution of material, publicly condoning, denying or grossly trivializing international crimes, as defined in the Statute of the International Criminal Court or the Charter of the International Military Tribunal directed against the group. Article 1(2) grants Member States the liberty to punish the aforementioned actions and/or expressions only when they are carried out in a way 'likely to disturb public order or which is threatening, abusive or insulting'. The objective of this provision is to provide an extra safety net for States concerned with free speech issues. However, it could be argued that the offences listed in this article, per se, disturb public order and/or are threatening, abusive or insulting. Article 1(2), therefore, complicates the conceptualization of the types of speech and activities which can be deemed to fall within the realm of hate speech as incorporated in this article and, also, indirectly presupposes that they can be carried out or expressed without resulting in harm. The absence of any jurisprudence of the Court of Justice of the EU renders even more difficult the conceptualization of what speech or conduct are likely to incite violence or hatred against a group or a member of such a group. Article 3 notes that criminal penalties for the offences should be 'effective, proportionate and dissuasive' with the conduct included in Article 1 being punishable by penalties of between 1 year and 3 years' imprisonment. In a nutshell, hate speech, as presented in this article, is an offence punishable by criminal law, insofar as it is directed at the defined groups, occurs in the public domain and is serious enough to 
incite to violence or hatred against the targeted group. It does not follow the lower threshold adopted by, for example, Article 20 of the ICCPR which prohibits any advocacy of national, racial or religious hatred that constitutes, inter alia, incitement to discrimination or Article 4 of the ICERD which prohibits the dissemination of ideas based on racial superiority or hatred. Further, Article 1(4) of the Framework Decision provides Member States with the possibility of restricting offences to the denial of crimes, which have been established by a final decision of a national and/or international court when dealing with the treatment of international crimes in hate speech.

In relation to hate crime, although no definition of the phenomenon is provided for, this document sets out a provision on racist and xenophobic motivation which is to constitute an aggravating circumstance in the determination of penalties. More particularly, Article 4 provides that:

For offences other than those referred to in Articles 1 and 2 Member States shall take the necessary measures to ensure that racist and xenophobic motivation is considered an aggravating circumstance, or, alternatively that such motivation may be taken into consideration by the courts in the determination of the penalties.

Therefore, this document embraces a higher threshold in terms of what is to constitute hate speech in comparison with the two UN documents, discussed earlier, since it punishes the public incitement to violence or hatred and not, for example, discrimination as referred to in Article 20 (2) ICCPR. The threshold is further heightened by the incorporation of the possibility of States limiting speech which harms public order and/or is threatening, abusive or insulting, thereby, incorporating further conditions to what can be prohibited or not. Further, this document only punishes certain types of speech, namely that which targets race, colour, religion, descent or national or ethnic origin and considers only racist and xenophobic motivation to constitute an aggravating circumstance. It does not protect other characteristics such as gender identity or sexual orientation. The possible justification of the initial objectives of institutions to prevent the reoccurrence of World War II atrocities with a focus on the racist element of the Nazi regime and the gradual development of the human rights movement, post-ICCPR and ICERD, meant that new conceptualizations of equality were not integrated into older documents. Such justifications cannot be used for the 2008 Framework Decision which is recent and arose after the broadening of the notion of equality. This demonstrates a clear hierarchy of hate, at least within the EU framework which opted to develop a Framework Decision tackling only racist and xenophobic speech 
and crime, rather than a general document to tackle hate speech and hate crime or a counterpart which would protect sexual orientation and gender identity. The European Parliament recognized the weakness in this and recommended that the Commission proposes a 'recast' of the Framework Decision to include 'other forms of bias crime and incitement to hatred, including on grounds of sexual orientation and gender identity'. $\underline{52}$ Whatever the possible or plausible explanations for the state of affairs, the need to amend is urgent. The generic clauses of the UNs and the Council of Europe have been interpreted by monitoring bodies to include the protection of sexual orientation and sexual orientation and gender identity, respectively. Several years down the line the EU directly incorporated sexual orientation, but not gender identity, into its main human rights treaty. Moreover, the ECtHR in Vejdeland v. Swedenrecognized that 'discrimination based on sexual orientation is as serious as discrimination based on race, origin or colour'. $\underline{53}$ Interestingly, in 2016, Human Rights Council adopted a resolution on 'Protection against violence and discrimination based on sexual orientation, and gender identity,,$\underline{54}$ which mandates the appointment of an independent expert. This demonstrates a strong, albeit slow, development in the arena of LGBTI rights. The expert has been mandated with the duty to, inter alia, look at gaps in the implementation of existing international human rights law but not to recommend possible improvements to the current international legal framework. As such, there is no legal, historical or other justification to maintain the current framework without amending it to ensure an equal incorporation of protected characteristics. In fact, the above-mentioned institutions have tried, through a patch work approach such as the interpretation of 'sex' by the UNs to include 'sexual orientation' demonstrates the realization that these characteristics should be part and parcel of the legal framework.

Additional protocol to the cybercrime convention concerning the criminalization of acts of a racist and xenophobic nature committed through computer systems

The Cybercrime Convention is a Council of Europe document, which aims to tackle crime committed through computer systems. It has been ratified by 47 countries, including nonCouncil of Europe (non-CoE) countries, such as the United States, which has observer status in the Council of Europe. The Additional Protocol to the Convention on Cybercrime criminalizes racist and xenophobic acts committed through computer systems. The Additional Protocol entered into force in 2006 and there are currently 29 States Parties which have ratified it. Article 2 defines racist and xenophobic material as: 
Any written material, any image or any other representation of ideas or theories, which advocates, promotes or incites hatred, discrimination or violence, against any individual or group of individuals, based on race, colour, descent or national or ethnic origin, as well as religion if used as a pretext for any of these factors.

The Protocol obliges States Parties to adopt legislative and other measures to criminalize intentional dissemination of racist and xenophobic material through computer systems, racist and xenophobic motivated threat and denial, gross minimization, approval or justification of genocide or crimes against humanity, all through computer systems. It also criminalizes the intentional aiding and abetting of the above-mentioned offences. The Protocol does not criminalize the possession and procurement of racist and xenophobic material as does the Convention in relation to child pornography. $\frac{55}{}$ Free speech considerations mark several provisions of the Protocol. More particularly, in relation to the dissemination of material, a party may reserve the right not to attach criminal liability to this conduct where the material is not hateful or violent and where other effective remedies are available. $\underline{56}$ For racist and xenophobic insult, a States Party may require that the insult exposes persons to hatred, contempt or ridicule or it may choose not to apply this article in whole or in part. A safeguard is also incorporated in the realm of denying or minimizing genocide or crimes against humanity, holding that States Parties can opt for criminalizing such behaviour if it incites hatred, discrimination or violence or may choose not to apply this article in whole or in part. Moreover, the Protocol's Explanatory Note holds that all the acts, minus insults, must be public to protect Article 8 of the ECHR. $\underline{57}$

So, this Protocol tackles hate speech online but only insofar as it falls within the realm of racism and xenophobia, while Article 2 of the Protocol also incorporates the grounds of religion to fall within the framework of racist and xenophobic material. The drafters of the Protocol, which was created in 2003 and adopted in 2006, did not consider it important to broaden the spectrum of hate speech to incorporate homophobic, biphobic and transphobic speech. As with the Framework Decision, this demonstrates a clear hierarchy of what the Council of Europe, in this case, considers to be important, relevant and significant to criminalize in the realm of hate speech.

\section{The national level: The example of Cyprus}

The UNs, the Council of Europe and the EU have not set a good example in terms of inclusiveness and equality in their approaches to hate speech and hate crime with the continuing hierarchy and prioritization of certain types of hatred related to race, ethnicity 
and religion. Notwithstanding that there exists no international or European document obliging countries to take measures to tackle hate speech and hate crime, which target characteristics such as sexual orientation and gender identity, one can find several EU Member States which have done so themselves, without external pressure. For purposes of brief illustration, I refer to Cyprus as this case shows going beyond supranational obligations as well as the potential impact of the supranational hierarchy on the formulation of the law. In Cyprus, the Law Amending the Criminal Law 87(I) 2015 incorporated Article 99A into the Criminal Code which holds that:

Any person who intentionally, publicly and in a manner which is threatening or abusive or insulting incites or instigates orally or through the press or via any document or picture or by any other means, violence or hatred directed against a group of persons or a member group of persons who are determined on the basis of their sexual orientation or gender identity, shall be guilty of an offense and, on conviction, shall be liable to imprisonment not exceeding three (3) years or to a fine not exceeding five thousand euros $(5,000)$ or to both such penalties.

This article has been separated from the provision on racist and xenophobic hate speech in Law 134(1)2011 on Combating Certain Forms and Expressions of Racism and Xenophobia through Criminal Law, which was passed for purposes of incorporating the Council Framework Decision which did not include the two grounds referred to in Article 99A of the Criminal Code. Interestingly, Article 99A does not incorporate the potential condition that such speech harms public order, as does the relevant article on racist and xenophobic speech of the law harmonizing the Framework Decision. $\underline{58}$ However, the penalties for homophobic and transphobic speech are lower, namely 5000 Euros and/or 3 years of imprisonment while the penalty for racist and xenophobic speech is 10,000 Euros and/or 5 years of imprisonment. In addition, Article 99A holds that, for a prosecution to take place, the approval of the Attorney General is sought, something not required by the racist and xenophobic counterpart and an element which constitutes an extra obstacle in the process.

Therefore, this is an example of a country which chose to go beyond the grounds protected by the Framework Decision. However, Cyprus drafted a law to harmonize the Framework Decision and this law reflected the Framework Decision in its entirety and, its focus on racism and xenophobia, the country's subsequent decision to protect the grounds of sexual orientation and gender identity was incorporated elsewhere, namely, the Criminal Code. Unfortunately, the penalties associated with Article 99A, therein, were lower than those 
associated with racist and xenophobic speech while no legal developments have yet to be made in the field of hate crime targeting sexual orientation and gender identity.

\section{Conclusion}

There is no equality in the legal framework of hate speech and hate crime as established by the UN, the CoE and the EU. There is no incorporation of the grounds of sexual orientation and gender identity as protected grounds in the realm of hate speech and hate crime, even in more recent documents such as the Framework Decision. This does not match the development of the international human rights movement which, over the years and since the inception of older human rights documents, has extended its understanding of key terms such as solidarity, equality and non-discrimination to go beyond the realm of racial and religious discrimination. This reality, in addition to the original foundation of the UN as an institution to prevent the reoccurrence of World War II atrocities which heavily emanated from racist ideals, is of particular relevance to the discussion on the current hierarchy of hate which exists in the framework of both hate speech and hate crime in international and European documents. While the state of development of international human rights law during the time of adoption of the ICCPR is relevant to Article 20(2) and can serve as a justification for the exclusion of other relevant grounds, such justifications cannot be used for more recent documents such as the Framework Decision, discussed earlier, or as an excuse for the non-adoption of a separate international covenant to counterpart the ICERD in the field of sexual orientation and gender identity. On a national level, countries, such as Cyprus, which had no concrete legislation on hate speech and hate crime before the Framework Decision, have gone beyond supranational requirements but in a flawed way, as demonstrated earlier. There is also no synergy or compatibility in that the thresholds developed in the four major instruments, namely, Article 20(2) ICCPR, Article 4 (ICERD), the Framework Decision and the Additional Protocol dealing only with computer systems, differ with the broadest conceptualization of what is to be prohibited amounting from Article 4 ICERD and the narrowest from the Framework Decision. As such, and for purposes of ensuring equal rights for all victims of hate speech and hate crime, and to be able to adhere to the basic values of international human rights law, concrete steps need to be taken by the three relevant institutions to create, for example, counterparts, such as the ICERD and the Framework Decision, but within the sphere of sexual orientation and gender identity. More particularly, the backbone of international human rights law, namely the Universal Declaration of Human Rights, emanates from the premise that 'all human beings are born free and equal in dignity and rights'. For this to be real and valid in today's world, 
and for purposes of ensuring a non-discriminatory and inclusive approach, equal attention needs to be paid to homophobic, biphobic and transphobic speech and crime within the framework of international human rights law. Otherwise, the current hierarchy of hate will continue to exist.

Declaration of Conflicting Interests

The author(s) declared no potential conflicts of interest with respect to the research, authorship, and/or publication of this article.

\section{Funding}

The author(s) received no financial support for the research, authorship, and/or publication of this article.

\section{Notes}

1.As recognized by the European Commission in the Report from the Commission to the European Parliament and the Council on the Implementation of Council Framework Decision 2008/913/JHA on Combating Certain Forms and Expressions of Racism and Xenophobia by Means of Criminal Law (European Commission 2014), accessed 17 July 2018 , para.

3.4, http://eur-lex.europa.eu/legalcontent/EN/TXT/?\%20uri=celex:52014DC0027.

2.The term 'United Nations' was used for the first time in the Universal Declaration of Human Rights.

3.J. Morsink, The Universal Declaration of Human Rights, Origins, Drafting and Intent (eds. Philadelphia: University of Pennsylvania Press, 1999), p. 36.

4.List of ratifications, accessed 15 August 2017, http://www.coe.int/en/web/conventions/full-list//conventions/rms/0900001680306052.

5.Fundamental Rights Agency (2009) Homophobia, transphobia and discrimination on grounds of sexual orientation and gender identity in the EU Member States: Summary of findings, trends, challenges and promising practices. Report, European Union.

6.Ibid. 49. 
7.This term is used by myself in previous work such as N. Alkiviadou: The Hierarchy of Hate: Mixed Signals in the Combat Against Hate Speech VerfBlog, 2018, accessed 17 July 2018, https://verfassungsblog.de/the-hierarchy-of-hate-mixed-signals-in-the-combatagainst-hate-speech/ DOI: 10.17176/20180206-124217 and also M. Walters, S. Wiedlitzk and A. Owusu-Bempah Hate Crime and the Legal Process: Options for Law Reform. (Report, University of Sussex, 2017).

8.For such discussions see, inter alia, E. Henize 'Viewpoint Absolutism and Hate Speech', The Modern Law Review 69(4) (2006): 543-582; I. Hare and J. Weinsten, Extreme Speech and Democracy. (OUP, 2011); A. Buyse, 'Contested Contours - the Limits of Freedom of Expression from an Abuse of Rights Perspective - Articles 10 and 17 ECHR', in E. Brems and J. Gerards, eds, Shaping Rights in the ECHR: the Role of the European Court of Human Rights in Determining the Scope of Human Rights (Cambridge, 2013), p. 185; E. Heinze, Hate Speech and Democratic Citizenship. (OUP, 2016); M. Herz and P. Molnar, The Content and Context of Hate Speech: Rethinking Regulation and Responses (Cambridge, UK: Cambridge University Press, 2012).

9.For such discussions see, inter alia, J. Schweppe and M. Walters, The Globalisation of Hate: Internationalising Hate Crime? (OUP, 2016); T. Bakken, 'Liberty and Equality Through Freedom of Expression: The Human Rights Questions Behind Hate Crime laws' International Journal of Human Rights4(2), (2013), p. 1.

10.U. Belavusau, Freedom of Speech: Importing European and US Constitutional Models in Transitional Democracies (1st ed. London, UK: Routledge, 2013), p. 41.

11.R. Smolla, 'Free Speech in an Open Society', in A. A. Knopf, eds (New York, 1992), pp.166-167.

12.M. Slagle, 'An Ethical Exploration of Free Expression and the Problem of Hate Speech', Journal of Mass Media Ethics, 24, p. 242.

13.K. Greenawalt, Speech, Crime and the Uses of Language. (OUP, 1989), Ch.2, 148.

14.CAT Concluding Observations: Moldova (2009) 'CAT/C/MDA/CO/2', para. 27; CAT Concluding Observations: Poland (2007) 'CAT/C/POL/CO/4', para. 20, CAT Concluding Observations: Mongolia (2010) 'CAT/C/MNG/CO/1', para. 25.

15.European Court of Human Rights, Fact Sheet on Hate Speech, 2013, 1. 
16.T. McGonagle, 'The Council of Europe against Online Hate Speech: Conundrums and Challenges' Expert Paper, Institute for Information Law, Faculty of Law, accessed 15 August 2017, http://hub.coe.int/c/document_library/get_file?\%20uuid=62fab806-724e435a-b7a5-153ce2b57c18\&groupId=10227, p. 3.

17.CERD Concluding Observations: United States of America (2001) 'CERD/C/59/Misc.17/Rev.3', para.12.

18.CERD General Recommendation 15: Measures to Eradicate Incitement to or Acts of Discrimination (1994) 'A/48/18' at p. 114, para. 4.

19.Motion for a European Parliament resolution on establishing a common legal definition of hate speech in the EU (2017).

20.Report from the Commission to the European Parliament and the Council on the implementation of Council Framework Decision 2008/913/JHA on Combating Certain Forms and Expressions of Racism and Xenophobia by Means of Criminal Law COM 27 (2014), p. 9.

21.Council of Europe's Committee of Ministers Recommendation 97 (20) on Hate Speech.

22.The Observer and The Guardian v. The United Kingdom (ECHR,26 November 1991, App. No 13585/88), para. 59.

23.Gündüz v. Turkey, App. No 35071/97 (ECHR, 4 December 2003, App. No. 59405/00) para. 40; Erbakan v. Turkey (ECHR 6 July 2006, App. No 59405/00) para. 56.

24Vejdeland and Others v. Sweden (ECHR 9 February 2012, App. No 1813/07) para. 54.

25.Ibid.

26.Fundamental Rights Agency, 'Hate Speech and Hate Crimes against LGBT Persons' 1 (2009), $1, \quad$ accessed 28 August 2018, https://webcache.googleusercontent.com/search?q=cache:8tmj2MF0_7MJ:https://fr a.europa.eu/sites/default/files/fra_uploads/1226-Factsheet-homophobia-hate-speechcrime_EN.pdf $+\& \mathrm{~cd}=1 \& \mathrm{hl}=\mathrm{en} \& \mathrm{ct}=\mathrm{clnk} \& \mathrm{gl}=\mathrm{cy}$. 
27.Defined by The European Institute for Gender Studies as 'Each person's deeply felt internal and individual experience of gender, which may or may not correspond to the sex assigned at birth, including the personal sense of the body (which may involve, if freely chosen, modification of bodily appearance or function by medical, surgical or other means) and other expressions of gender, including dress, speech and mannerisms.

28.R. Kiska, 'Hate Speech: A Comparison Between The European Court of Human Rights and the United States Supreme Court Jurisprudence' Regent University Law Review 25 (2012), pp. 107, 110.

29. Motion for a European Parliament resolution on establishing a common legal definition of hate speech in the EU (2017).

30.Vejdeland and Others v. Sweden (ECHR 09 February 2012, App. No 1813/07) para. 55.

31.Organization for Security and Cooperation in Europe: 'Hate Crime Laws: A Practical Guide' (2009). OSCE Report.

32.E. McLaughlin and J. Muncie, The SAGE Dictionary of Criminology. (Thousand Oaks: SAGE, 2006), p. 196.

33.OSCE-ODIHR 'Hate crime laws: A Practical Guide', (2009) 7, accessed 10 February 2015, http://www.osce.org/odihr/36426?\%20download=true. OSCE Report.

34.J. Schweppe, A. Haynes and M. A Walters, Lifecycle of a Hate Crime: Comparative Report. (University of Sussex, ICCL, 2018).

35.H. Corcoran, D. Lader and K. Smith, Hate Crime, England and Wales, 2014/2015. (University of Sussex, Home Office, 2015) p. 22.

36.P. Iganski and A. Sweiry, 'How “Hate”Hurts Globally', in J. Schweppe and M. Walters, eds The Globalisation of Hate: Internationalising Hate Crime? (OUP, 2016, 14).

37.Ibid.

38.Ibid.

39.Šečić v. Croatia (ECHR 31 May 2007, App. No. 40116/02) para. 67. 
40.Identoba and Others v. Georgia (ECHR 12 May 2015, App. No. 73235/12) para. 67.

41.Human Rights Committee General Comment 18, 'Non-Discrimination' (1994) HRI/GEN/1/Rev. 1 para. 12.

42.Article 1.3, Charter of the United Nations 1945.

43.Toonen v. Australia (1994, App. No. 488/1992) U.N. Doc CCPR/C/50/D/488/1992.

44.HRC Concluding Observations: Chile (2007) 'CCPR/C/CHL/CO/5', para. 16; HRC Concluding Observations: San Marino (2015) 'CCPR/C/SMR/CO/2', para.7; HRC Concluding Observations: Austria (2007) 'CCPR/C/AUT/CO/4', para. 8.

45.Salgueiro da Silva Mouta v. Portugal(ECHR 21 December 1999, App. No. 33290/96); Dudgeon v. United Kingdom, (ECHR 22 October 1981, App. No 7525/76); Smith and Grady v. the United Kingdom (27 September 1999, App. Nos. $33985 / 96$ and 33986/96).

46.P.V. v. Spain (ECHR 30 November 2010, App. No. 35159/09); Goodwin v. United Kingdom (ECHR 11 July 2002, App. No.28957/95).

47.As noted in, inter alia, the Fundamental Rights Agency report entitled 'Protection Against Discrimination on Grounds of Sexual Orientation, Gender Identity and Sex Characteristics in the EU Comparative Legal Analysis' $(2015,8)$.

48.D. Mahalic and J. G. Mahalic, 'The Limitation Provisions of the International Convention on the Elimination of all Forms of Racial Discrimination' Human Rights Quarterly 9(1) (1987), p. 89.

49.CERD General Recommendation 1: States Parties' Obligations (1972) A/8718, para. 37.

50.CERD General Recommendation 35: Combating Racist Hate Speech (2013) CERD/C/GC/35, para. 8 .

51.ARTICLE 19, 'Policy Brief - Responding to Hate Speech against LBGTI People' (2013), p. 12. 
52.European Parliament Resolution of 4 February 2014 on the EU Roadmap against Homophobia and Discrimination on Grounds of Sexual Orientation and Gender Identity (2013/2183(INI)).

53.Vejdeland and Others v. Sweden (ECHR 09 February 2012, App. No 1813/07) para. 55.

\section{A/HRC/RES/32/2.}

55.Article 9, Additional Protocol to the Cybercrime Convention Concerning the Criminalisation of Acts of a Racist and Xenophobic Nature Committed Through Computer Systems.

56.Ibid., Article 3.2.

57.Explanatory Report to the Additional Protocol to the Convention on Cybercrime, Concerning the Criminalisation of Acts of a Racist and Xenophobic Nature committed through Computer Systems, para. 29.

58.Law 134 (I)/2011 on Combating Certain Forms and Manifestations of Racism and Xenophobia through Criminal Law 2011. 